CPB Netherlands Bureau for

Economic Policy Analysis

\title{
Optimizing the life cycle path of pension premium payments and the pension ambition in the Netherlands
}

We investigate the optimal arrangement of a fully funded pension system in a life cycle model calibrated on Dutch data. We analyse the importance of three factors: the fact that income generally increases with age, the presence of children in the early years of the household and the education level of the main earner of the household. Different education levels are associated with different slopes of the lifecycle income profiles in the data.
Both the upward sloping income profile and the presence of children in young households contribute to a delay of pension premium payments towards later working ages. Family size has a large impact on pension premiums and ambition.

\section{CPB Discussion Paper}

Harry ter Rele, Carolijn de Kok, Nicoleta Ciurila, Peter Zwaneveld 
CPB Netherlands Bureau for Economic

Policy Analysis

Sector 3 Labour, Educhtion And Pensions

CPB Netherlands Bureau for Economic Policy Analysis

Optimizing the life cycle path of pension premium payments and the pension ambition in the Netherlands

Harry ter Rele Carolijn de Kok Nicoleta Ciurilă $\quad$ Peter Zwaneveld 


\section{Summary}

We determine the optimal life cycle path of pension premiums during the working ages and pension benefits during retirement, assuming that households can choose these freely. The optimization takes into account the fact that incomes generally rise during the working ages and that children are generally present in young households.

A calibration of the model on Dutch data shows that the optimal pension scheme features an upward sloping path of pension premium rates instead of the flat premium rate prevailing under the current pension system. Both the upward sloping income profile and the presence of children in young households contribute to a delay of pension premium payments towards later working ages. The optimal level of pension benefit is lower than under the current pension system. The optimal pension system increases welfare by an amount that equals a 3.4 percent increase in lifetime consumption if no borrowing constraints are imposed and 2.8 percent if, more realistically, we impose these constraints.

Differentiating the path of pension premiums and benefits according to the level of educational attainment of the main income earner brings only small additional welfare gains compared to the situation in which pension premium rates are based on the path of average income in the economy. The lower return on pension assets expected in the future contributes to a further delay of optimal pension premiums during the working ages and leads to a lower optimal pension benefit after retirement. Family size (i.e. the number of children) has a large impact on optimal pension premiums and the optimal pension ambition.

Policy conclusions from our results should carefully weigh the calculated welfare gain against possible negative and positive effects of non-modelled aspects.

\section{Introduction}

Over 90 percent of employees participate in a funded occupational pension scheme in the Netherlands ${ }^{1}$. Combined with the first pillar pension (pay as you go financed public pension), this forms the major part of retirement income for the vast majority of the population. The occupational schemes generally feature pension premiums that linearly depend on income: each pension fund typically levies flat premium rates on incomes in excess of a franchise. In general, no additional factors are considered. Furthermore, the pension ambition, the level of pension benefits that the schemes aim at, generally only depends on lifetime labour income. Here too, no further analysis takes place as to whether other circumstances should play a role as well.

The aim of this paper is to determine the influence of a number of factors on the path of optimal pension premiums and benefits. We also compute the increase in the household's welfare in the case that these factors are taken into account when establishing the pension premiums and benefits. The first factor is the expected income profile of the household. This is usually increasing with age during the working life. The second factor is the change in family size and composition during the life that are due to the presence of children in the household. As this paper shows, both factors represent a reason to shift a part of the pension premiums paid from the beginning of the working career to the end, while under the current scheme the pension premium rates are constant over the working life. The third factor that we analyse is the level of educational attainment of the household. As we show in the paper, households in which the main earner has a low level of educational attainment can expect a rather flat income profile over the working life, while households in which the main earner has a medium or high level of educational attainment can expect a steep income profile. Consequently, the profile of optimal pension premium rates can potentially be quite different for the three categories of households.

\footnotetext{
${ }^{1}$ https://www.pensioenfederatie.nl/website/the-dutch-pension-system-highlights-and-characteristics
} 
We determine the path of optimal pension premiums and benefits in a life-cycle model in which the household earns a deterministic income. We consider that households can freely choose the desired path of pension premiums and pension benefits and they do so by maximizing lifetime utility from consumption. Because the income is certain, households only save for retirement. That is why throughout this paper we consider that optimal savings rates of the household are equal to optimal pension premium rates. Since the income and the return on pension assets are deterministic, the model is very tractable and admits an analytical solution. We set the deterministic income path over a household's life-cycle equal to the path of average income in the economy. In reality, people's income is stochastic, but the average income profile in the economy gives people (and pension funds) a reference in terms of what income profile to expect when they enter the labor market.

We calibrate the model on Dutch data. Our results show that taking into account the upward sloping income profile and the presence of children in young households leads to two changes in the second pillar pension schemes. First, we show that the optimal path of pension premium rates rises with age. Since people want to smooth consumption over their life, an upward sloping income profile means that people would like to borrow in the beginning of their working life and then repay the debt and save for retirement towards the end of their career. Moreover, households have higher consumption needs while children are present. That is why they would prefer to defer paying premiums to the pension system to older ages when children leave the household. Second, we show that the optimal pension benefit is lower.

The welfare gain from implementing the optimal pension premiums and benefits scheme is quantitatively important. Our analysis indicates that, relative to the current pension system, the optimal pension scheme would raise welfare by the equivalent of a 3.4 percent higher lifetime consumption in the case that no borrowing constraints are imposed. If, more realistically, we impose borrowing constraints, the welfare gain is equivalent to an increase in lifetime consumption of 2.8 percent. We also consider that households can have different income paths and family composition over the life cycle because of different levels of educational attainment of the main household earner. Differentiating optimal premium rates by taking into account the level of educational attainment of the main household earner brings small additional welfare gains for households with a lower level of educational attainment (a gain equivalent to 0.9 percent of lifetime consumption) compared with the situation when pension premium rates are based on the profile of average income in the Dutch economy. However, there is almost no additional welfare gain for households with medium and higher educational attainment. We also determine what a lower rate of return on pension assets implies for the optimal pension premiums and benefits. We obtain that households would find it optimal to shift even more of the premiums paid to the pension fund to the end of their working career. Optimal pension benefits are also lower.

The contribution of this paper is that it determines the optimal level of pension premiums and benefits taking into account simultaneously the upward sloping income profile, the changing family composition and the level of educational attainment of the household. Previous literature has analysed these factors separately. We also show the impact of borrowing constraints and of a lower interest rate on the optimal path of pension premiums and benefits.

By calibrating the model on Dutch data we contribute to the pension discussion in the Netherlands. In 2020, a new Pension Agreement was introduced in the Netherlands. One of its properties is that it makes the pension premiums actuarially fair and undoes the system of its implicit intergenerational transfer from the young to the old. It combines a constant (or 'flat') pension premium rate with an actuarially fair build up of pension wealth in individual accounts ${ }^{2}$. Age independent ('flat') pension premiums were an important element in the so called SER-advice of, among others, employers and employees on the new pension contract due to labor market effects (SER (2019), p.27). Age related

\footnotetext{
${ }^{2}$ For current participants in Individual Defined Contribution contracts, employers may opt for continuing the current age-dependent (and age-increasing) pension premium path (Ministry of Social Affairs and Employment (2020), p. 6).
} 
pension contribution rates are seldom encountered in the public pension system. They show a significant rise with age only in Switzerland ${ }^{3}$.

We show in this paper that there are two reasons to consider pension premiums that differ with age in the Dutch pension system. First, the income of the average Dutch household is increasing with age. Second, Dutch parents have to provide for their children in the beginning of their career, while later children leave households. Taking into account the level of educational attainment of the household would have a small impact on the path of pension premiums in the Netherlands.

The implementation of the upward sloping profile of pension premium rates that we find optimal in our paper may pose some problems in practice. We can think of two ways how to implement this in practice. The first solution is that employers accept that the pension costs related to their employees increase over their career. This may make employers reluctant to hire or keep older workers. The second way of implementing the optimal scheme is by increasing the size of the employee's premiums across the working life. In this case the net wage will increase less (or even decline) with age. If people have different preferences than the ones assumed in this paper, a smaller increase or a decline in their net wage may induce people to retire earlier.

This paper builds on the literature that analyzes the role of the life-cycle income profile and family composition on the optimal time path of consumption and savings. Attanasio and Weber (2010) and Nishiyama and Smetters (2007) use an approach in which the household planner takes account of household size by imputing standardized consumption in the utility concept. Standardized consumption reflects the consumption of each of the individual earners in the household. It is calculated by dividing family consumption by a factor that is larger than 1 for families with more than one member. This factor takes into account the fact that family consumption has to be shared with the other members of the household as well as of the fact that multi person households benefit from economies of scale. ${ }^{4}$ However, these papers do not include the utility of the other members of the household. In this approach the other members are only a cost factor by reducing the standardized consumption of the household. Other papers do include the consumption of other household members in the utility. Domeij and Klein (2013) do so by including the standardized consumption of all household members and also attach equal weights to them. Fuchs-Schundeln (2008), Scholz et al. (2006) and Laitner and Silverman (2012) also attach equal weights but impute per capita consumption rather than standardized consumption and therefore ignore the economies of scale involved in forming a multiple people household. Bick and Choi (2013) explore the implications of the different ways of taking into account the size and composition of the household. They show that these lead to diverging optimal paths of consumption but express no preference for either of these.

We use two approaches in our paper. Our preference lies with the model as used in Domeij and Klein (2013), referred to hereafter as the family model, which takes into account all members of the household in the utility function. It uses a more comprehensive measure of welfare and thus may be a better way to determine the pension scheme that maximizes welfare from a social perspective. For calculations that impute the baseline assumptions we also present the results of the model where the utility concept only takes account of the standardized consumption that accrues to the income earners in the household, as the literature is not conclusive yet. It is the same model as in Attanasio and Weber (2010) and Nishiyama and Smetters (2007) and referred to here as the earner model.

Cui (2008) focuses on the effect of life-cycle earnings on pension premiums in individual defined contribution pension systems and finds that substantial welfare gains can be obtained by making the time

\footnotetext{
${ }^{3}$ For details, see www.bsv.admin.ch/bsv/en/home/social-insurance/bv/grundlagen-und-gesetze/grundlagen/sinn-undzweck.html. Finland also has age related pension contribution rates but in this case the rise with age is small (see https://www.etk.fi/en/finnish-pension-system/financing-and-investments/pension-contributions/).

${ }^{4}$ For a three person household, for instance, the factor is smaller than 3 . Section 3 elaborates on this.
} 
path of pension premiums age dependent. Scott et al. (2021) substantiate the low enrollment of young households in 401(k) plans in the US. They find that for young households that are liquidity constrained and expect an upward sloping income path, it is optimal to pay no pension premiums up until their late 30s. We obtain the same results in the model with borrowing constraints. Additionally, we analyze what the presence of children in the household implies for optimal pension premiums. Summers (1984) and Elmendorf (1996) have analyzed the role of the return on capital on optimal savings. We follow their methodology, but add a realistic income profile, family composition and borrowing constraints to their analysis. We also look at households with different levels of educational attainment.

Our paper has a number of limitations. First, we base our analysis on the average paths of incomes and household composition in the population. In reality there is a lot of heterogeneity in these paths. However, under some conditions, the results of our paper will not deviate much from a model in which households receive idiosyncratic shocks around the average path. In this case, if people are rational, they will hold liquid savings to protect their consumption from fluctuations due to the shocks, while pension savings will still reflect the path they expected when they entered the labour market, the average path. Moreover, if the social planner (or pension fund) sets the path of optimal premiums in the economy based on the concept of ex ante utility, i.e. utility of a household when she enters the labor market, then the results can be expected to be very similar to the ones obtained in this paper. Second, we do not take into account the fact that the return on capital is stochastic. This would probably change our results quantitatively. However, we do not expect that it will change the result that the optimal path of pension premiums is upward sloping with age. This is also the case for the bequest motive, another issue of which we abstract in our analysis. Third, we abstract from other factors that influence a household's savings pattern, for example the presence of study loans or mortgages. We expect that the introduction of these factors will strengthen our results. Since people borrow in the beginning of their life for studying and buying a house, they would prefer to shift the payment of pension premiums closer to the retirement age. Fourth, we consider that people supply labor inelastically and want to retire exactly at 65 years of age. Lower pension premiums at younger ages result in less pension wealth at a certain age and reduce the possibility to retire early, if desired. Consequently, the optimal pension premium path should also take into account the desired retirement age of a household. Finally, higher pension premiums close to the retirement age make pension benefits more dependent of the ability to work at that age. Hence, policy conclusions from our results should carefully weigh the calculated welfare gain against possible negative and positive effects of non-modelled aspects.

The rest of this paper is structured as follows. Section 2 discusses the life cycle models that are used to carry out the optimization and Section 3 the data we use to calibrate the model. Section 4 presents the results and a sensitivity analysis that explores the robustness of the results with respect to some parameters in the model. We also determine the optimal pension premium path and the welfare gain for different educational levels. Section 5 presents the results in the case that borrowing constraints are imposed. Section 6 concludes the paper.

\section{The models}

Firstly, we describe the model we use to find the optimal life cycle path of consumption by only taking into account the utility of the earners in the household (Section 2.1). Secondly, in Section 2.2 we present a model in which the utility of all members of the household is considered. Section 2.3 describes how we model the current pension system. In order to measure the welfare gain of the outcomes of these models relative to those of the current pension system, we calculate the equivalent variation of consumption. The formulas with which we do that are presented in Section 2.4. 


\section{$2.1 \quad$ Earner model}

A household enters the labor market at 25 years of age. She earns a gross income equal to $y_{t}$ at each age $t$ until retirement. Afterwards, the household earns a benefit from the public pay as you go pension system $\left(a o w_{t}\right)$. We fix the retirement age $(r a)$ at 65 years. The household chooses each period how much to consume $\left(c_{t}\right)$ and how much wealth to accumulate $\left(a_{t}\right)$ by maximizing the present value of the utility of standardized consumption. We assume that a household starts without wealth and cannot have negative wealth when ceasing to exist. The probability to survive until age $t$ is equal to $\psi_{t}$, with a maximum age of $T$. We consider that households discount the future with $\beta$ and that the gross rate of return on wealth equals $R$. Preferences are described by a CRRA utility function (relation 5 ).

The problem that the household solves is described as follows:

$$
\begin{gathered}
\max _{\left\{c_{t}, a_{t}\right\}} \sum_{t=1}^{t=T} \beta^{t-1} \psi_{t} u\left(c_{t}\right) \\
y_{t}+R a_{t-1}+t r_{t}=c_{t}+\operatorname{tax}_{t}+a_{t} \quad, t<r a \\
a o w_{t}+R a_{t-1}+t r_{t}=c_{t}+t a x_{t}+a_{t} \quad, t \geq r a \\
a_{0}=a_{T}=0 \\
u\left(c_{t}\right)=\frac{\left(\frac{c_{t}}{e q_{t}}\right)^{1-\sigma}}{1-\sigma}
\end{gathered}
$$

where $r a$ is the retirement age, $\operatorname{tax}_{t}$ is the amount of tax that the household pays, aow $w_{t}$ is the gross benefit from the pay-as-you-go pension pillar (AOW - Algemene Ouderdomswet), $u\left(c_{t}\right)$ is the utility function and $\sigma$ is the inverse of the elasticity of intertemporal substitution. The per capita transfers $t r_{t}$ come from the fact that a fraction of the population alive at time $t-1$ dies and the bequests are divided between the members still alive at time $t$. The variable $e q_{t}$ represents the equivalence factor at time $t$ adjusting the income based on the amount of members in the household.

Since both the income of the household and the return on wealth are deterministic, the household only saves in order to afford consumption during retirement. That is why throughout this paper we equate the savings of households with pension premiums and the wealth accumulated for retirement with pension assets. The household saves at each age $t$ a sum given by the following expression:

$$
p_{t}=R a_{t-1}-a_{t}
$$

Throughout the working life $p_{t}$ is positive and represents the flow savings (pension premiums) of the household. After the retirement age $p_{t}$ turns negative since households draw down their assets. The absolute value of $p_{t}$ represents the pension benefit (or pension ambition) of the household.

We consider that the household insures herself for longevity risk. We combine the budget constraints from equations 2 and 3 into a lifetime budget constraint (all derivations of the equations can be found in the Appendix):

$$
\begin{array}{r}
\psi_{1} c_{1}+\frac{\psi_{2} c_{2}}{R}+\ldots+\frac{\psi_{T} c_{T}}{R^{T-1}}+\psi_{1} \operatorname{tax}_{1}+\frac{\psi_{2} \operatorname{tax}_{2}}{R}+\ldots+\frac{\psi_{T} \operatorname{tax}_{T}}{R^{T-1}}=\ldots \\
\psi_{1} y_{1}+\frac{\psi_{2} y_{2}}{R}+\ldots+\frac{\psi_{r a-1} y_{r a-1}}{R^{r a-2}}+\frac{\psi_{r a} a o w_{r a}}{R^{r a-1}}+\ldots+\frac{\psi_{T} a o w_{T}}{R^{T-1}}
\end{array}
$$

Using the first order conditions of the maximization problem, we can derive a closed form solution of the consumption at time $t$ :

$$
c_{t}=c_{1}(\beta R)^{\frac{t-1}{\sigma}}\left(\frac{e q_{1}}{e q_{t}}\right)^{\frac{1-\sigma}{\sigma}}\left(\frac{1-\omega_{t}}{1-\omega_{1}}\right)^{\frac{1}{\sigma}}
$$


where $\omega_{t}$ represents the percentage tax rate at time $t$. This value of the tax rate differs before and after retirement (see Table 1). The optimal savings ratio is simply equal to the optimal total savings of the household $a_{t}-R a_{t-1}$ divided by the household's income $y_{t}$.

The specification of equation 8 shows that the shape of the optimal life cycle path of family consumption depends on three terms. The first term $(\beta R)^{\frac{t-1}{\sigma}}$ captures the net effect of the time discount factor and the return on wealth. If the return on wealth exceeds the time discount factor $(R \beta>1)$ households save more and delay consumption to older ages. The converse is true if the return on wealth is lower than the time discount factor $(R \beta<1)$.

The third term $\left(\frac{1-\omega_{t}}{1-\omega_{1}}\right)^{\frac{1}{\sigma}}$ captures the impact of taxes on relative net incomes before and after retirement: a relatively low level of taxation after retirement forms an incentive to save more during the working years and thus to shift consumption to the retirement phase. ${ }^{5}$ The size of the effect for these two terms depends on the value of $\sigma$ : a high value for this parameter reflects a low valuation of increases in consumption relative to decreases in it and thus a high preference for constancy of consumption levels throughout the life cycle. This results in a lower impact of these terms. A low value for $\sigma$ reflects the opposite.

The second term, the ratio of equivalence factors $\left(\frac{e q_{1}}{e q_{t}}\right)^{\frac{1-\sigma}{\sigma}}$, captures the impact of changes in family size. It reflects the fact that a high number of children in the household reduces the benefit that each of its individual members, and thus also the earners, has from family consumption. This individual benefit, or standardized consumption, is calculated by dividing family consumption by the equivalence factor. The size of the effect of this term on the optimal life cycle path of consumption differs from the other two terms because it works through two channels that work in opposite directions. The first is that a high equivalence factor (more children) lowers standardized consumption, and thus also the benefit that earners of the household have from family consumption in these years. This lowers the marginal utility of a unit of family consumption for the earners which, in this model, has a negative effect on optimal family consumption. The second channel is that the lower individual benefit also increases the marginal utility of consumption of its members, entailing that the earner's utility valuation per unit of consumption increases. This raises optimal standardized and family consumption and this effect becomes larger the higher the value of $\sigma$. If $\sigma$ is larger than 1 the latter of the two effects dominates and optimal family consumption tends to be high in years with a high equivalence factor.The opposite holds if $\sigma$ is smaller than 1.

Equation 8 also shows that the shape of the life cycle path of family consumption is fully independent of the years in which the family earns its income. Incomes only impact on the levels of consumption and it does this via the lifetime budget constraint (Equation 7). This independence results from the fact that we do not impose borrowing constraints at this point.

\section{$2.2 \quad$ Family model}

The family model can be seen as an extension of the earner model where the consumption of the children is included in the utility function. To implement this variable, we denote the average number of members in the household by $n_{t}$. The utility function (equation 5 ) is adjusted as follows:

$$
u\left(c_{t}\right)=n_{t} \frac{\left(\frac{c_{t}}{e q_{t}}\right)^{1-\sigma}}{1-\sigma}
$$

The consumption at time $t$ for the family model becomes:

$$
c_{t}=c_{1}(\beta R)^{\frac{t-1}{\sigma}}\left(\frac{n_{t}}{n_{1}}\right)^{\frac{1}{\sigma}}\left(\frac{e q_{1}}{e q_{t}}\right)^{\frac{1-\sigma}{\sigma}}\left(\frac{1-\omega_{t}}{1-\omega_{1}}\right)^{\frac{1}{\sigma}}
$$

\footnotetext{
${ }^{5}$ For simplicity, average and marginal tax rates in both phases are set equal. This is further discussed in the appendix.
} 
Note that the relative number of members in a household at time $t$ has a positive effect on the consumption at time $t$. Compared to the situation where the utility of children is not taken into account (Equation 8), the number of members of the household plays a more important role in determining the consumption at time $t$.

\subsection{The current pension system}

We model the current system, here referring to the system after the introduction of the new Pension Agreement, by imputing flat (age independent) pension premium rates during the working years as well as flat pension benefits after retirement. In order to enable a pure comparison of welfare effects with the systems derived in the two models above, we assume that are no intergenerational transfers. This means that the wealth that is accumulated by the pension premiums is fully paid out. The pension premium rate that is levied on gross incomes above the franchise typically averages $21 \%{ }^{6}$. Around two-thirds (14\%) of it is paid by the employer, while roughly one third $(7 \%)$ is paid by the employee. The contribution of the employer is included in our income data as well. Therefore, in order to determine the pension savings under the current pension system, we adjust the incomes by dividing them by 1.14. Pension premiums are levied on incomes in excess of a franchise $f$ and as both partners earn an income the franchise is deducted twice. We assume that as a result of general equilibrium effects, both the employee's and employer's part of the pension premiums are effectively borne by the employee. This follows from the fact that the Netherlands are a small open economy and, as a result of international competition, employers don't have the financial room to raise labour costs and that therefore these costs are fixed. Hence, we use the next formula to obtain pension savings $\left(p_{t}\right)$ :

$$
p_{t}=\left(\frac{y_{t}}{1.14}-2 f\right) 0.21
$$

Pension benefits are fixed in real terms and can be seen as annuities. On the year of retirement, we calculate how much pension benefit an individual receives per year based on the pricing definition of a one-dollar fixed premium per year annuity:

$$
A=\sum_{t=1}^{T-r a} \frac{\psi_{t \mid r a}}{(1+R)^{t}}
$$

where $A$ is the amount of wealth required to be able to pay for a one-dollar annuity, $\psi_{t \mid r a}$ is the probability that a household reaches age $t$ given that he reached the retirement age and $R$ is the rate of return. The amount of annual pension benefits $(p b)$ that are paid from the accumulated wealth is equal to:

$$
p b_{t}=\frac{a_{r a-1}}{A}
$$

Because of the way it is computed, the pension benefit is always age invariant under the current pension system. However, under the optimal pension system the pension benefit can vary with age.

\subsection{Deriving the equivalent variation and the effect on welfare}

Besides finding the optimal path of pension savings and the optimal pension ambition, we want to measure its additional value compared to the current pension system. We express the welfare improvement in terms of consumption levels. We calculate the equivalent variation, i.e. the percentage change in annual consumption required by households in order to be indifferent between the current pension system and

\footnotetext{
${ }^{6}$ The average premium of the five biggest pension funds in 2020 in the Netherlands: ABP, PFZW, PBFbouw, PBMT and Shell pension fund.
} 
the pension system with age dependent pension premium rates (the optimal pension system):

$$
\sum_{t=1}^{T} \beta^{t} \psi_{t} u\left(c_{v p, t}\right)=\sum_{t=1}^{T} \beta^{t} \psi_{t} u\left((1+\delta) c_{f p, t}\right)
$$

where $\delta$ represents the consumption equivalent, $c_{v p}$ is the consumption of households when the pension premium varies with age and $c_{f p}$ is the consumption when the pension premium is flat, equal to the current value of the pension premium rate. A positive value for the consumption equivalent $\delta$ indicates that the current pension system has a lower welfare: households require a higher level of annual consumption in order to be just as well off as in an economy with age dependent pension premium rates.

Because we are using a CRRA utility function (see equation 5), the formula above simplifies to:

$$
\sum_{t=1}^{T} \beta^{t} \psi_{t} u\left(c_{v p, t}\right)=(1+\delta)^{1-\sigma} \sum_{t=1}^{T} \beta^{t} \psi_{t} u\left(c_{f p, t}\right)
$$

The formula for the consumption equivalent becomes:

$$
\begin{gathered}
\delta=\left(\frac{V\left(c_{v p}\right)}{V\left(c_{f p}\right)}\right)^{\frac{1}{1-\sigma}}-1 \\
V\left(c_{v p}\right)=\sum_{t=1}^{T} \beta^{t} \psi_{t} u\left(c_{v p, t}\right) \\
V\left(c_{f p}\right)=\sum_{t=1}^{T} \beta^{t} \psi_{t} u\left(c_{f p, t}\right)
\end{gathered}
$$

We compute the consumption equivalent in two distinct ways. In the first case, we simply replace the consumption of households under the age dependent pension premium regime and under the current pension system, respectively, in formula 16 . This will be the standard way of computing the consumption equivalent and of assessing welfare gains throughout the paper.

In the second case, we also analyze the impact of a different schedule of pension premiums and benefits on the tax level prevailing in the economy and incorporate it in the welfare quantification. More specifically, we acknowledge in this case the fact that a change in the pension system may also affect the amount of taxes paid throughout a household's life and, hence, the government budget. This is because pension premiums are not taxed. We consider that if tax revenues are higher under the optimal pension system than under the current pension system, the difference in revenues is transferred back to households. We transfer these extra government revenues in such a way that the time varying consumption levels are adjusted across all ages equally in relative terms. To the contrary, if tax revenues are lower under the optimal pension system than under the current system, an extra tax is levied on households in order to rebalance the government budget. As in the rest of the paper, we consider that the extra taxation or transfers have no influence on the amount of labor supplied by households, i.e. labor is inelastic.

We determine the lifetime difference in the present value of the tax paid when a flat pension premium rate of $21 \%$ is compulsory $\left(\operatorname{tax}\left(c_{t, f p}\right)\right)$ and when we implement an age dependent pension premium rate (the optimal pension premium) $\left(\operatorname{tax}\left(c_{t, v p}\right)\right)$ :

$$
\zeta=\frac{\sum_{t=1}^{T} \frac{\psi_{t} \operatorname{tax}\left(c_{t, v p}\right)}{(1+)_{t}^{t-1}}-\sum_{t=1}^{T} \frac{\psi_{t} \operatorname{tax}\left(c_{t, f p}\right)}{(1+d)^{t-1}}}{\sum_{t=1}^{T} \frac{\psi_{t} c_{t, v p}}{(1+d)^{t-1}}}
$$

where $d$ is the discount factor. The consumption in the model with age dependent premium rates is adjusted at each age $t$ with $\zeta$ percent:

$$
c_{t, v p}^{a d j}=c_{t, v p}(1+\zeta)
$$

After correcting for the difference in taxes, we determine the value of the lifetime utilities $\left(V\left(c_{f p}\right)\right.$, $\left.V\left(c_{v p}^{a d j}\right)\right)$. We substitute these in equation 16 in order to obtain the consumption equivalent. 


\section{Calibration of the models}

Household income. In order to determine the life-cycle income profile of Dutch households, we use the Inkomenspanelonderzoek (IPO) data provided by Statistics Netherlands (CBS). The sample period covers the years 2006-2013. The measure of income that we use is the gross income of households net of financial income. The pension premiums payed by the employer are included in the incomes. We make the following sample selections. First, we only take into account households with a head aged between 25 and 65 years. Second, we eliminate households that earn an income from self-employment because this type of income is very volatile. Finally, we restrict the sample to households that have two earners throughout our sample period. Consequently, we are left with a number of 222.330 observations in the sample.

We transform the gross income net of financial income to real values by dividing through the Consumer Price Index. We eliminate year fixed effects from the data. Finally, for the age between 25 and 65 years, we set the gross income of a household aged $t$ years $y_{t}$ equal to the mean of the income of all households with a head aged $t$ years in our sample. After the age of 65 years, we set $y_{t}$ equal to the value of the AOW benefit (see Table 1).

Since our latest data point corresponds to the year 2013, we try to incorporate the latest developments on the Dutch labor market. More specifically, we try to incorporate the fact that Dutch households have substantially increased the age at which they retire from the labor market. To this end, we extend the peak of the income path we obtain from the CBS data until the age of 57 and let it decrease with $7 \%$ until the age of 65 . This adjustment is based on Van Tilburg et al. (2019).

For the analysis in Section 4.5, we divide the households into three groups based on the educational attainment of the household head: 1) lower education households: BO (basisonderwijs - primary education) and VMBO (voorbereidend middelbaar beroepsonderwijs - pre-vocational education); 2) medium education households: MBO (middelbaar beroepsonderwijs -secondary vocational education), HAVO (hoger algemeen voortgezet onderwijs - higher general secondary education) and VWO (voorbereidend wetenschappelijk onderwijs - university preparatory education); 3) higher education households: HBO (hoger beroepsonderwijs - higher vocational education) and WO (wetenschappelijk onderwijs - university).

Equivalence factors and number of household members. The equivalence factors are the ones provided by the CBS. These attach the value of 1 to the first adult in the household, 0.37 to any other adult and a value between 0.15 and 0.33 to every under age child. For a household aged $t$ years, we set the equivalence factor equal to the mean of all equivalence factors corresponding to households with a head aged $t$ years. We do the same in order to determine the number of household members representative for a household with a head aged $t$ years in the Netherlands.

Figures $1 \mathrm{a}$ and $1 \mathrm{~b}$ show the profile of the equivalence factor and the number of household members for households with a head aged between 25 and 65 years. The actual incomes and standardized incomes are shown in Figure 2. It shows that the shape of household income from work and the public pension is hump shaped. Incomes are highest between the ages of around 45 and 57 and decline afterwards as a result of lower rates of labour participation. Standardized incomes show a more prolonged rise up until the age of 57 before declining due to the decreasing numbers of children in the household above the age of 45 .

Values calibrated for the parameters of the model. We use values from the literature to calibrate the parameters of the model as well as characteristics of the Dutch economic environment and the Dutch tax and transfer system.

Table 1 summarizes the parameters used to calibrate the model. We set the baseline rate of return 
(a) Average equivalence factor of a household

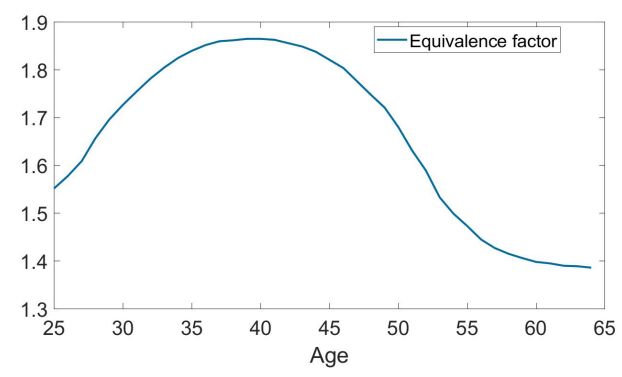

(b) Average number of members in a household

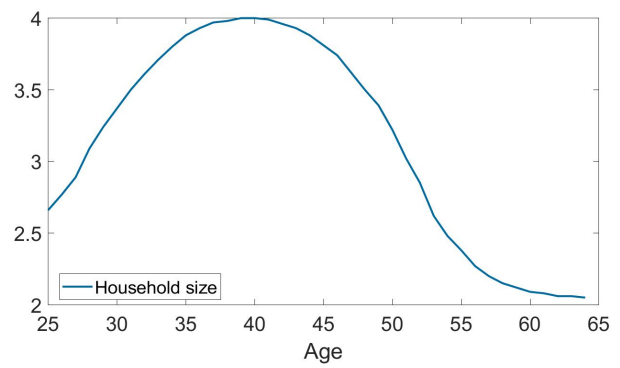

Figure 1: On the left we show the average equivalence factors of the households, on the right we show the average number of members in a household.

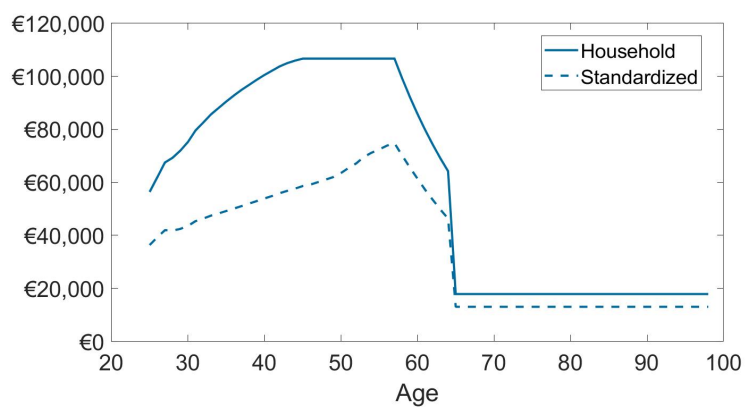

Figure 2: Actual and standardized income of average household (including imputed employer pension contributions)

on assets $R$ equal to 1.014 , based on an expected nominal return on pension assets of $4 \%^{7}$, an inflation rate of $2 \%$ and costs of the pension fund amounting to $0.6 \%$ of total assets. In our model the rate of return on assets is deterministic, while in reality the expected returns of the pension fund may contain a risk premium. That is why we also present in section 4.4.3 the results obtained with a lower rate of return on assets, equal to 0.4 percent. Calibrating the model with a lower rate of return on assets strengthens our results.

We set the parameter $\sigma$ equal to 2, that corresponds to an elasticity of intertemporal substitution $\frac{1}{\sigma}$ equal to 0.5 . This is the mean of the values estimated in the literature (Havranek et al. (2015)). The estimations for the time preference parameter $\beta$ range between 0.93 and 0.99 (Alan and Browning (2010), French (2005), Gourinchas and Parker (2002), Guvenen and Smith (2014)). We choose a value of time preference that corresponds to an annual discount factor that is equal to $R$, i.e. $\beta=\frac{1}{R}=0.986$. We present robustness checks of the results for the values of $\sigma$ and $\beta$ in Section 4.4.

The probability to survive until age $t\left(\psi_{t}\right)$ is obtained from Statistics Netherlands (CBS). This declines with age, see Figure 3.

\section{Results}

In this section we describe the results of the earner and the family model. We ignore borrowing constraints at this point. In section 4.1 we show the welfare effect of the optimization in monetary terms by calculating its equivalent variation in comparison with the current flat pension premium. In section 4.2 we determine the welfare gain that can be achieved by keeping the pension premium rates flat as in the current pension

\footnotetext{
${ }^{7}$ https://www.abp.nl/english/investments/, section Investment Results. However, future rates of return are very uncertain.
} 
Table 1: Parameter calibration

\begin{tabular}{|lcc|}
\hline Parameter & Explanation & Value \\
\hline$\sigma$ & inverse of elasticity of & 2 \\
$\beta$ & intertemporal substitution \\
$\mathrm{R}$ & time preference & 0.986 \\
$\omega_{t}$ & gross return on savings & 1.014 \\
$\omega_{t}$ & tax rate working life & $38 \%$ \\
$\mathrm{~T}+25$ & tax rate retirement & $20 \%$ \\
$\mathrm{ra}+25$ & Maximum number of years & 98 \\
$\mathrm{~d}$ & Retirement age & 65 \\
aow & discount factor & $1.4 \%$ \\
\hline
\end{tabular}

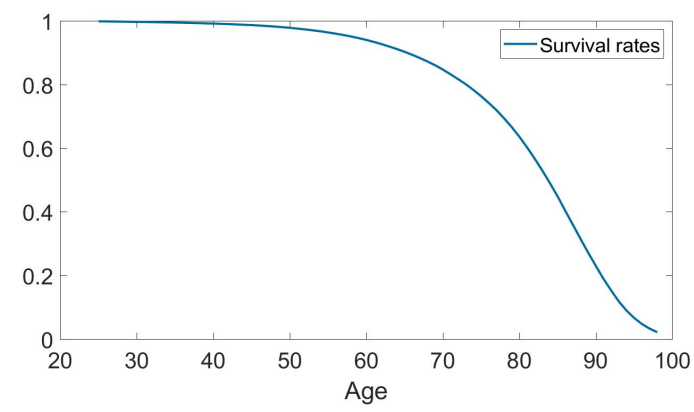

Figure 3: Probabilities to survive until age $t$ at the age of 20

system, but optimizing this flat rate with our model. In the subsequent subsections we carry out an analysis that explores the impact of changes in family size on the outcomes (section 4.3) and explore the sensitivity of the results to three parameter values: time preference $\beta$, the inverse of the elasticity of substitution $\sigma$ and the return on wealth (section 4.4). This section concludes by performing the optimization for three different educational levels (section 4.5).

\subsection{Optimal pension premium and benefits}

Figure 4 presents the results for the family and earner model. It shows that the optimal pension premium rates differ substantially from those under the current flat premium system. These differences originate from changes in standardized incomes across the life cycle (see Figure 2). This pattern of standardized incomes leads to a continuous decline in the marginal utility of income for each of the family members until the age 57 and a rise afterwards. In both models this in turn leads to an optimal pattern of life cycle savings ratios (figure 4c) that, after being negative in the first decades, rises until this age and declines afterwards. This contrasts markedly with the current flat premium outcome in which it is roughly constant. This pattern is more pronounced in the family model as, other than in the earner model, the utility of all household's members count in the optimization. At the age of 57 savings ratios reach a level of around 30 percent in the earner model and even 40 percent in the family model. Optimal household wealth in the earner model peaks at just over 700 thousand euros (Figure 4a), almost 100 thousand more than that in the flat premiums system, and slightly over 500 thousand in the family model.

The life cycle path of family consumption (Figure 4b) follows the specifications of Equation 7 for the earner model and Equation 9 for the family model. It is highest in the years in which the equivalence 
(a) Optimal wealth

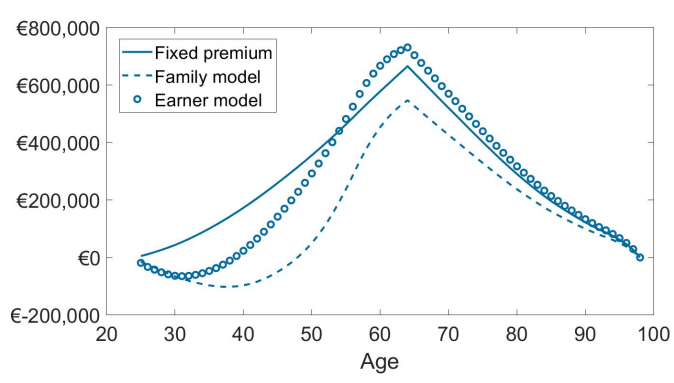

(c) Optimal savings ratio

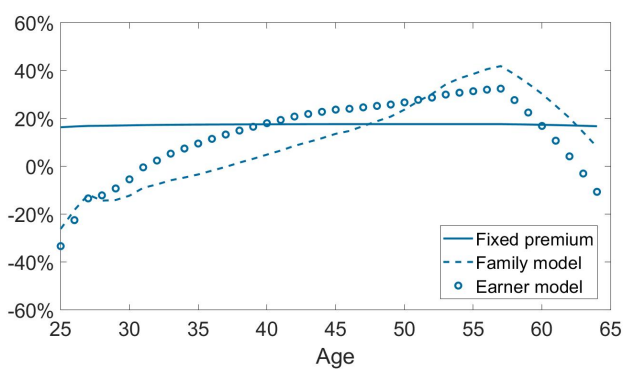

(b) Optimal consumption

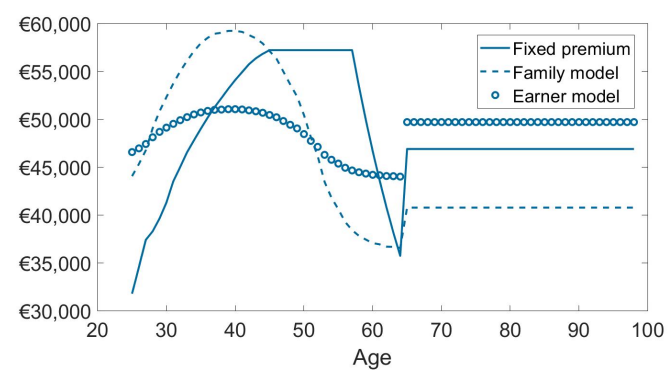

(d) Optimal pension benefits including AOW

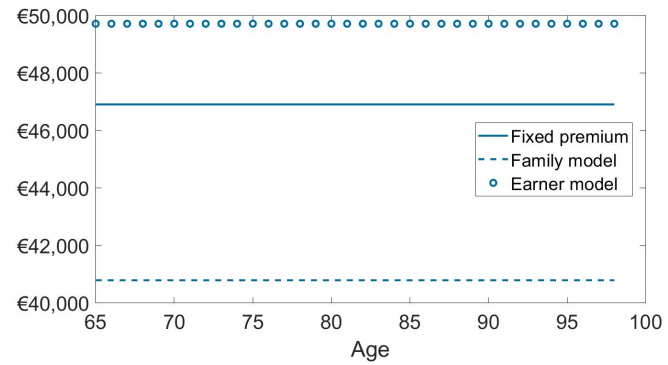

Figure 4: The current pension system (solid line), the family model (dashed line) and earner model (circles): optimal wealth, consumption, savings ratio and pension benefits.

factor is highest, especially in the family model. In the earner model this raises family consumption if $\sigma$ is larger than 1, as is the case in our baseline analysis. As is explained in Section 2.1, the relatively high cost of the presence of children at these ages raises the marginal utility of the part of family consumption that accrues to the earners and in turn raises optimal family consumption. In the family model this effect is even larger because the children's utilities are also included in the optimization. The tax incentive on pension savings however increases savings during the working years and curbs consumption. This incentive results from the fact that pension savings can be deducted from income in the working phase and that in this phase marginal tax rates are generally higher than after retirement. This is also the cause of the upward jump in consumption at the age of 65 .

Another important finding of this analysis is that in our preferred family model optimal family consumption after retirement and pension benefits (including the AOW) turn out to be substantially lower than under the current system (figures $4 \mathrm{~b}$ and $4 \mathrm{~d}$ ). This indicates that a lower pension ambition raises lifetime welfare in this model. In the earner model however optimal consumption and pension turn out to be higher.

The optimal pension benefits turn out to be age invariant exactly as under the current pension system. This is due to our assumption that $R \beta=1$. In this case the discount factor used by the households to discount future consumption is equal to the return on wealth, so households have no incentive to defer consumption or consume in advance during the retirement years. If $R \beta>1$, households are relatively more patient and prefer to defer consumption to the future. Consequently, the optimal pension benefits are increasing with age. The sensitivity analysis in section 4.4 .1 presents this case. If $R \beta<1$, the reverse is true: households are impatient and prefer to consume more in the beginning of their retirement period. Hence optimal pension benefits decrease with age. The sensitivity analysis in section 4.4 .3 presents such a case.

The welfare gains from optimizing the pension premiums and the pension ambition are presented in Table 2. The first column presents the consumption equivalent computed using formula 16. The second column presents the consumption equivalent for the case in which we correct the consumption path with 
the differences in tax revenues cashed by the government under the current and the optimal pension system, respectively (see section 2.4).

In the family model, households require a 3.4 percent higher lifetime consumption under the current pension system in order to achieve the same level of lifetime utility as under the optimized pension system. If we apply the tax adjustment as discussed in section 2.4, the welfare gain rises to an equivalent of 4.0 percent extra consumption. The higher figure results from the tax return obtained by households under the optimal pension system. This is made possible by the higher tax revenues cashed by the government: pension premiums are lowered and taxable income and consumption thus shifted to the working phase of the life cycle in which tax rates are higher than during the retirement phase. In the earner model, the total welfare gain is smaller and is equivalent to 2.4 percent extra consumption. With the tax adjustment the welfare gain corresponds to an increase of consumption of 2.0 percent. This lower result is caused by the increase in pension premiums and the resulting shift of taxable income and consumption to the retirement phase in which tax rates are lower.

Table 2: Optimal pension system vs current system - equivalent consumption

\begin{tabular}{|lll|}
\hline & $\begin{array}{l}\text { No tax } \\
\text { adjustment }\end{array}$ & $\begin{array}{l}\text { Tax } \\
\text { adjustment }\end{array}$ \\
\hline Family model & $3.4 \%$ & $4.0 \%$ \\
Earner model & $2.4 \%$ & $2.0 \%$ \\
\hline
\end{tabular}

\subsection{The optimal flat pension premium}

The analysis carried out in Section 4.1 allows pension premium rates and benefits to vary with age. We compare the welfare of this optimal pension premium and pension benefit scheme with the current flat rate pension system. We find sizeable welfare gains of 3.4 percent equivalent consumption in the family model and 2.4 percent in the earner model. These welfare gains stem from two sources: a) under the current pension system the pension premium rate is flat, while in the optimal pension system the pension premium rates are increasing with age and $b$ ) the current flat pension premium rate may not be optimal according to our model.

To check what part of the welfare gain that we obtain is due to the upward sloping path of the optimal pension premium rates, we compare in this section the results we presented in section 4.1 with the results of a model in which we search for a optimal flat (age invariant) pension premium rate. To this end, we determine the flat pension premium rate and the corresponding pension ambition that maximizes the lifetime welfare of the household in both the earner and the family model. The computation of the optimal flat premium is done through numerical optimization, because a closed form solution is not available.

Table 3: Optimal flat pension system

\begin{tabular}{|lll|}
\hline & $\begin{array}{l}\text { Pension premium } \\
\text { (\% of income) }\end{array}$ & $\begin{array}{l}\text { Pension benefit } \\
\text { (EUR) }\end{array}$ \\
\hline Family model & $17 \%$ & 40.599 \\
Earner model & $24 \%$ & 49.887 \\
Current system & $21 \%$ & 45.918 \\
\hline
\end{tabular}

Table 3 shows that the optimal flat pension premium rate in the family model is lower than in the current system: an optimal pension premium rate of 17 percent versus 21 percent for the same variable 
in the current system. In the earner model the optimal flat premium is higher than under the current pension system (24 percent versus 21 percent).

Table 4: Welfare gains compared to the current pension system

\begin{tabular}{|llll|}
\hline & $\begin{array}{l}\text { Optimal flat } \\
\text { pension premium }\end{array}$ & $\begin{array}{l}\text { Optimal variable } \\
\text { pension premium rate }\end{array}$ & $\begin{array}{l}\text { Difference in } \\
\text { welfare gain }\end{array}$ \\
\hline Family model & $0.3 \%$ & $3.4 \%$ & $3.1 \%$ \\
Earner model & $0.2 \%$ & $2.4 \%$ & $2.2 \%$ \\
\hline
\end{tabular}

Table 4 presents the welfare gains from optimizing the flat pension premium rate compared to the current pension system. It shows that in the family model the lower optimal flat pension premium rate increases welfare by the equivalent of a 0.3 percent increase in lifetime consumption (first column). Comparing this outcome to the 3.4 percent higher equivalent consumption obtained from allowing pension premiums to vary with age (second column), shows that the upward sloping pension premium rates are responsible for the majority of the welfare gain: it increases lifetime welfare as if consumption increases by 3.1 percent (third column). In the earner model the welfare gain of optimizing the flat pension premium rate is also very small. The welfare gain of 2.4 percent equivalent consumption we found in Section 4.1 therefore turns out to be almost entirely due to the fact that pension premium rates are allowed to depend on age.

\subsection{Effects of family size}

(a) Optimal wealth

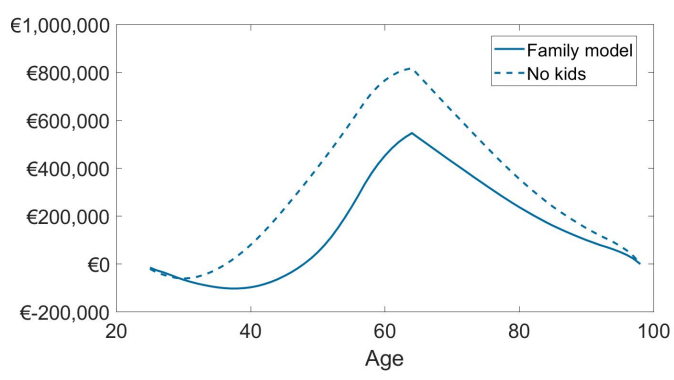

(c) Optimal savings ratio

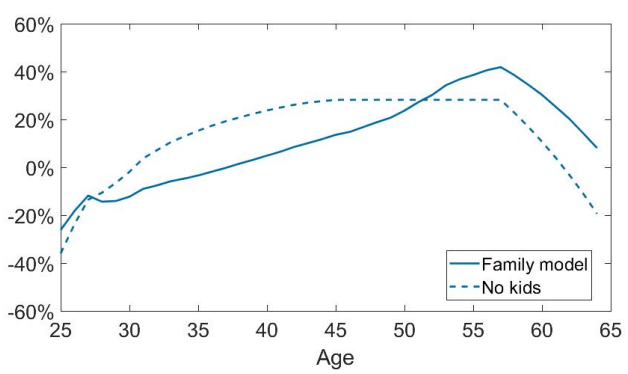

(b) Optimal consumption

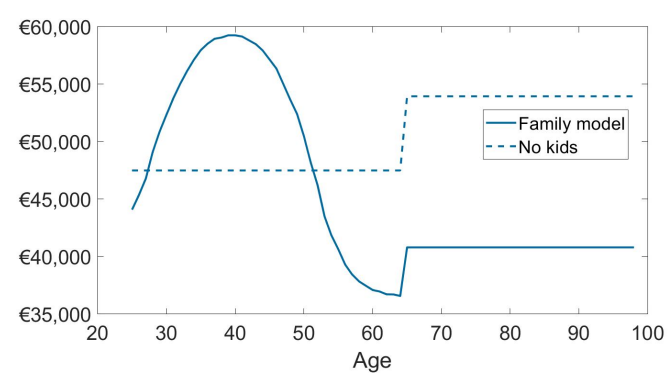

(d) Optimal pension benefits including AOW

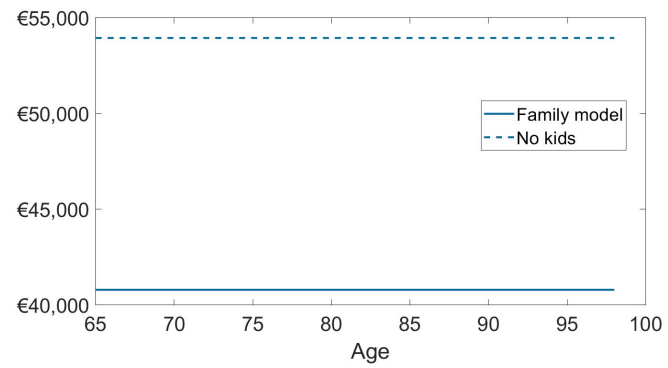

Figure 5: The family model in the baseline scenario (solid line) and the model with no kids in the household (dashed line): optimal wealth, consumption, savings ratio and pension benefits.

This section explores how the results that we obtained in Section 4.1 in the family model are driven by the changes in household size during the life cycle. It turns out that the impact of household size is quite substantial (see figure 5). A comparison of these outcomes with those if the households would have no children shows that the life cycle path of family consumption would be substantially flatter without 
children with only an upward jump at the retirement age as a result of the tax subsidy on pension savings. Consumption between the ages of 30 and 50 would be significantly lower reflecting the reduced utility of family consumption during these years. The optimal profile of pension premium rates would be considerably less progressive and pensions would be higher. Accordingly, the accumulation of wealth would be significantly higher.

\subsection{Sensitivity analysis}

The time preference parameter $\beta$ and the inverse of the elasticity of intertemporal substitution $\sigma$ are not estimated in our models but are assumed to have common values as in previous literature. The gross real return on assets $R$ was calibrated based on the current expected rate of return of the pension funds. In this section we evaluate the sensitivity of the results of the family model to different values of $\beta, \sigma$ and $R$.

\subsubsection{Sensitivity to the time preference parameter}

We first investigate what a higher value for the time preference parameter $\beta$ (0.99 rather than 0.986 ) implies for the results of the family model. The value of 0.99 represents the upper bound on the estimated values of $\beta$ found in the literature. Figure 6 presents the differences compared to the baseline calibration.

(a) Optimal wealth

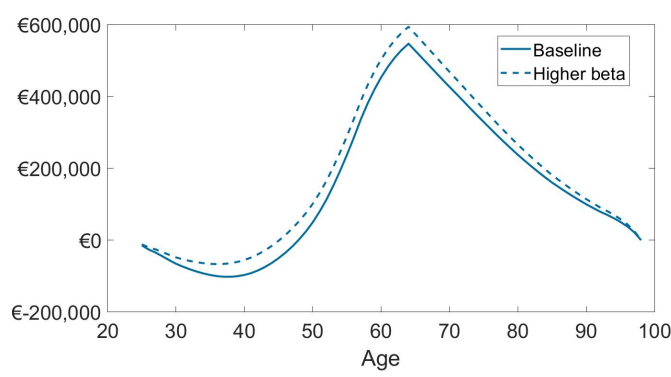

(c) Optimal savings ratio

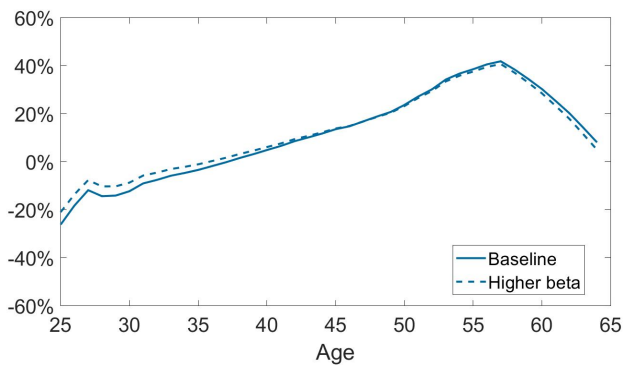

(b) Optimal consumption

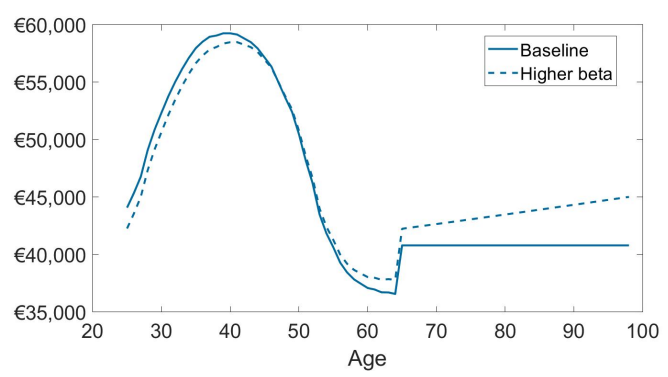

(d) Optimal pension benefits including AOW

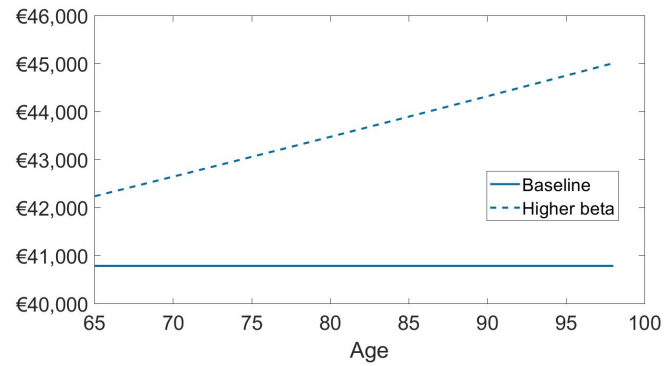

Figure 6: The family model when the discount factor $\beta$ equals 0.986 as in the baseline analysis (solid line) and 0.99 (dashed line): optimal wealth, consumption per earner and household and savings ratio.

With a higher value of $\beta$, the result that the optimal savings rate is low during the first years of working life and increases until the age of 57 remains unchanged. Optimal wealth now peaks at a slightly higher value than in the baseline. This is a reflection of the higher valuation of future consumption which leads to higher savings than in the baseline and a shift of consumption to later years. It also leads to pension levels that are higher and rise after retirement due to the fact that the capital return now exceeds the time discounting factor. 


\subsubsection{Sensitivity to the elasticity of intertemporal substitution}

A change in the elasticity of intertemporal substitution, the inverse of $\sigma$, changes the curvature of the utility function. A higher $\sigma$ means that it has a larger bending and this implies a lower positive valuation of increases in consumption relative to the negative valuation of decreases in it. As a result the importance of constancy of standardized consumption during the life cycle relative to total lifetime consumption shifts in favour of the former. We therefore expect the life cycle path of standardized and family consumption to flatten and savings to be affected correspondingly. The opposite holds if $\sigma$ is lower: we then expect differences in standardized and family consumption during the life cycle to increase.

(a) Optimal wealth

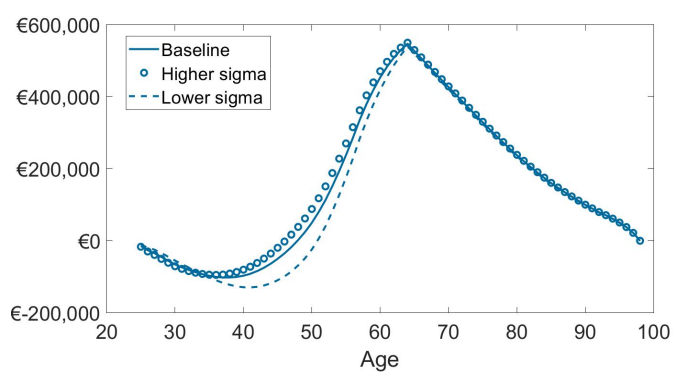

(c) Optimal savings ratio

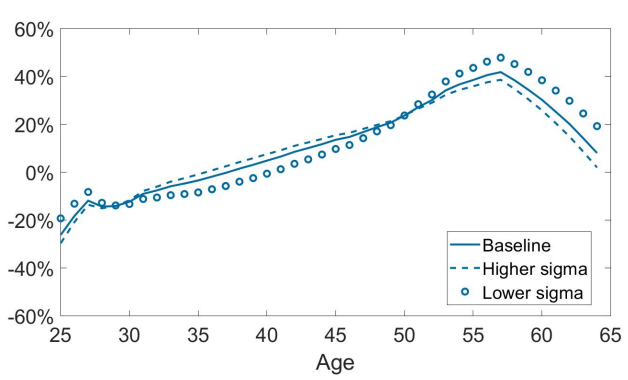

(b) Optimal consumption

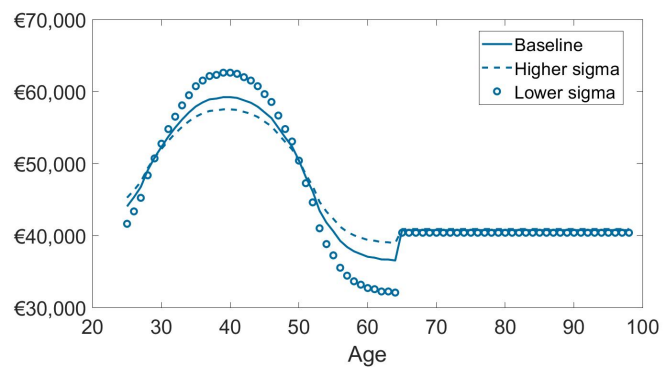

(d) Optimal pension benefits including AOW

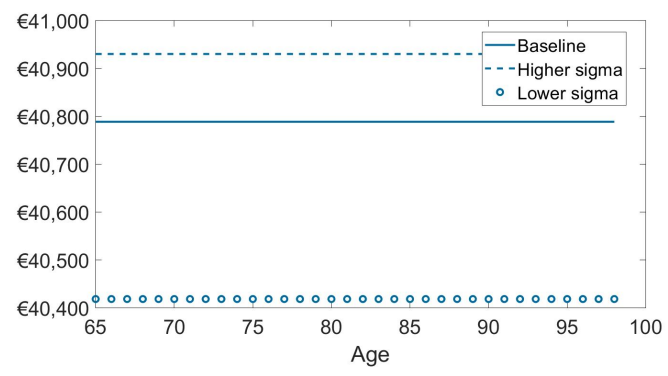

Figure 7: The family model with values for $\sigma$ of 1 (circles), 2 (solid line) and 4 (dashed line): optimal wealth, consumption, savings ratio and pension benefits.

Figure 7 shows the results if $\sigma$ is equal to 1 and 4, compared to the value of 2 we assume in the baseline calibration. They are in line with our expectations. Standardized and family consumption show a larger variation during the life cycle in the case of a lower $\sigma$ (Figure $7 \mathrm{~b}$ ). It more strongly responds to changes in the variables on the right hand side of Equation 9. Optimal savings ratios (7d) are lower than in the baseline until the age of around 50 and higher afterwards. Wealth peaks at approximately the same level. Accordingly optimal consumption (7b) after retirement and optimal pension benefits (7d) show small differences. Figure 7 also shows that a higher $\sigma$ leads to the opposite effects.

\subsubsection{Sensitivity to the rate of return}

Figure 8 shows the results of the model if we lower the calibrated rate of return on assets from 1.4 percent to 0.4 percent. We perform this robustness check for two reasons. First, we calibrate the rate of return on assets based on the expected return of the pension funds. Usually this value contains a risk premium, while our model is deterministic. Second, there has been a downward trend in real interest rates since the 1980's and there is a possibility that this will continue in the future as well. We show what are the implications of lower rates of return of the pension funds for the optimal pension premiums and pension benefits schedule.

The results show that in the case of a lower rate of return on assets households accumulate less 
(a) Optimal wealth

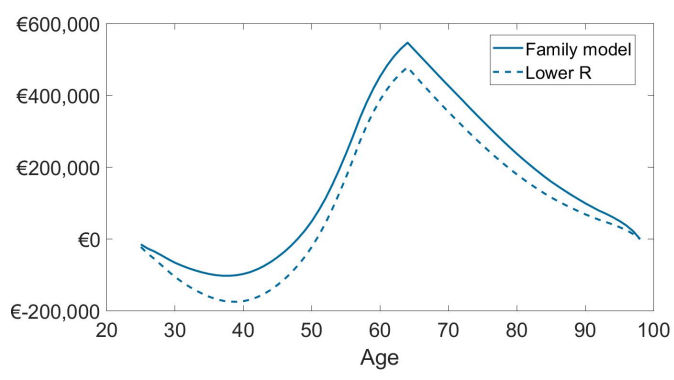

(c) Optimal savings ratio

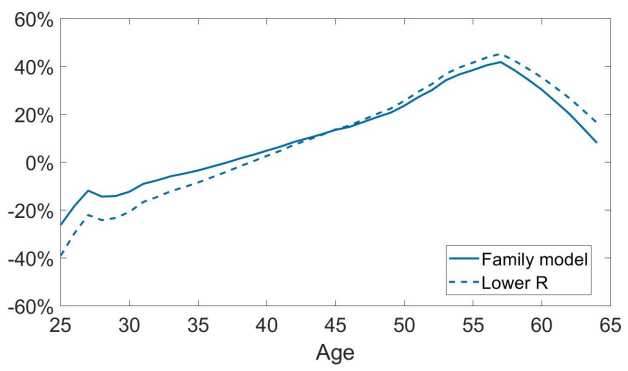

(b) Optimal consumption

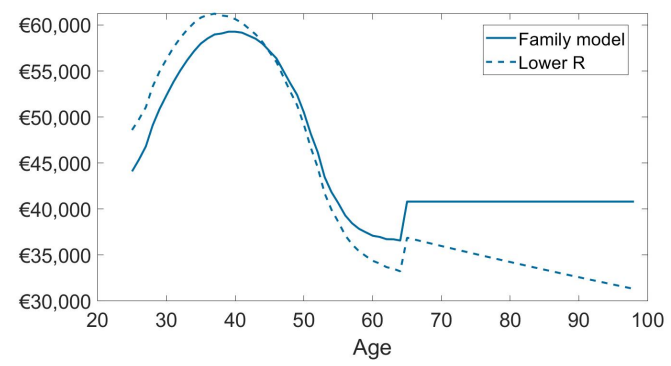

(d) Optimal pension benefits including AOW

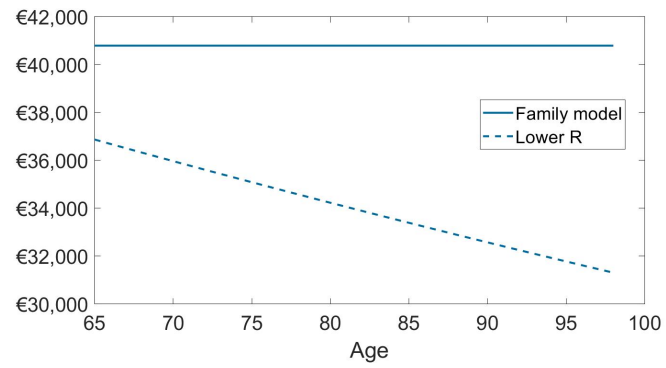

Figure 8: The family model in the baseline scenario where the rate of return equals 1.4 percent (solid line) and when the rate of return is equal to 0.4 percent (dashed line): optimal wealth, consumption, savings ratio and pension benefits.

wealth at the retirement age. Consequently, optimal pension benefits are also lower and households consume less in the second part of their life. Optimal savings ratios are lower in the first part of a household's working life and higher in the second part of the working life. This implies that households shift more of their retirement savings from the beginning towards the end of their career when the rate of return on assets is lower. Consequently, the scope of an upward sloping profile of pension premium rates is even higher in a low interest rate environment. The welfare gain from introducing the optimal pension premiums and benefits schedule is also higher, being equivalent to a $5.1 \%$ higher lifetime consumption.

\subsection{Different education levels}

In this section we determine the optimal savings ratios of households with different education levels. We also investigate the welfare gain that can be obtained by explicitly taking the level of educational attainment into account when setting pension contributions and benefits.

As we mentioned in Section 3, we group households in three groups of educational attainment according to the education level of the main income earner: low, medium and high. This splitting of households in different education groups is relevant because education level is observable and it is a rather stable characteristic over the life of a household. It is also determined rather early on in the working life of a household. Hence pension premiums can potentially be set differently based on this characteristic of the household head.

Households with different levels of educational attainment exhibit significant differences in terms of the lifetime income profiles (Figure 10a). More specifically, households with a higher educational attainment have a steeper increase in income over their working life than households with medium and low educational attainment. They also face a sharper decline in income after retirement. This is a result of the fact that the public pension $(\mathrm{AOW})$ is a flat rate system and does not depend on earnings during the working years. Households with a low educational attainment have a rather flat income profile over 
their life.

There are also differences between households with different educational attainment in terms of how family composition evolves over the life-cycle (Figure 9). Households with a low educational attainment have children earlier in their life than households with a medium and high educational attainment.

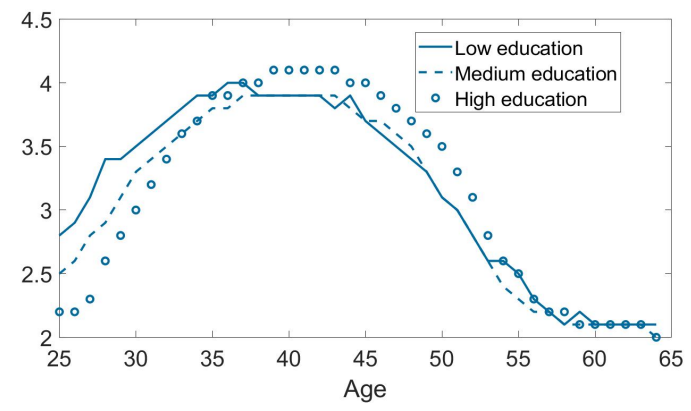

Figure 9: Average number of children in the household per education level

Figure 10 presents the results of optimizing the family model for the three types of households. Because of the steeper increase in income over the life-cycle, households with a higher level of educational attainment have a profile of optimal savings ratios that is slightly more progressive than the one of the households with low and medium educational attainment (Figure 10d). Although the income profile of households with a low educational attainment is rather flat, their optimal savings ratio is also progressive, albeit less than in the case of the households with medium and high education levels. This is because of the presence of children in the early life of the household.

(a) Gross income

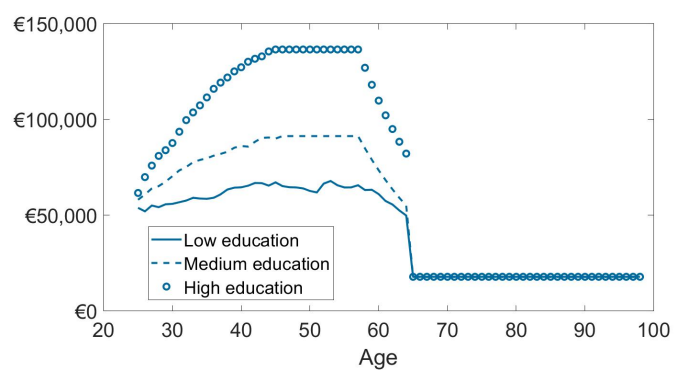

(c) Optimal consumption

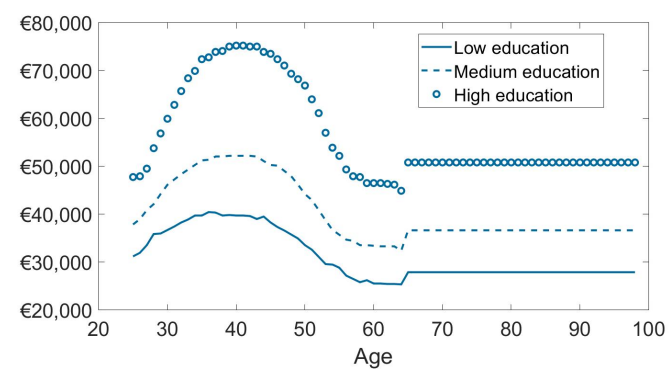

(b) Optimal wealth

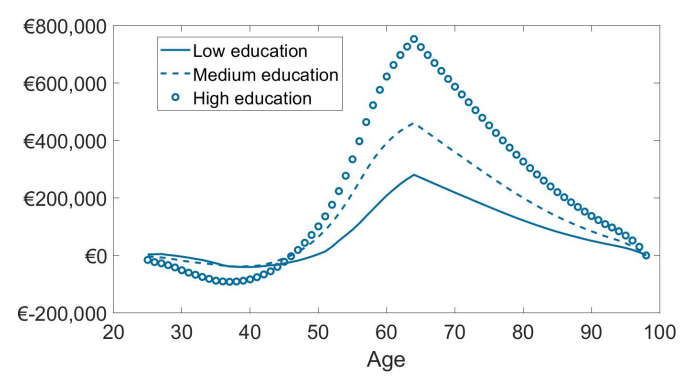

(d) Optimal savings ratio

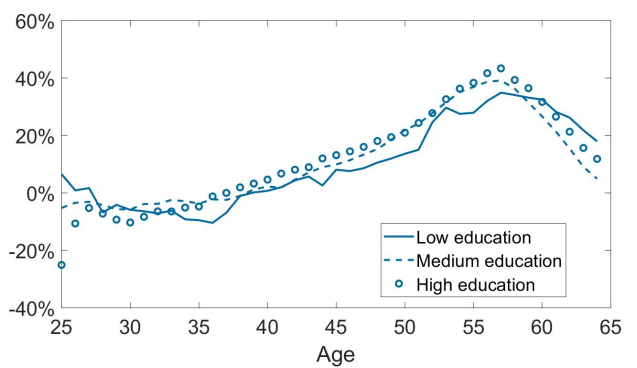

Figure 10: The family model for a household with a low education level (dashed line), a medium education level (solid line) and a high education level (circles): household income (including gross AOW and employer contribution pension premium), optimal wealth, consumption and savings ratio.

We investigate whether differentiating the path of pension contributions and the level of benefits for households with different educational attainments brings important welfare gains. To this end, we compute the consumption level that households with low, medium and high educational attainment would 
obtain if pension funds (or a social planner) would impose the premium rates derived from the model that uses the average income path of Dutch households and the average number of children present in the household (section 4.1, Figure 4c). We compare the resulting consumption paths with the optimal consumption profiles for each education level (Figure 10c). We compute the consumption equivalent, i.e. the annual percentage increase in consumption required by households in the case that pension contributions are based on the average income and average number of children of Dutch households in order to be just as well off as in the case that pension contributions are set at the optimal level corresponding to their education group.

We present the consumption equivalent for each level of educational attainment in Table 5 . There is a small welfare gain from setting pension premium rates equal to their optimal level in the case of households with a low level of educational attainment (equivalent to a $0.9 \%$ increase in lifetime consumption). However, households with a medium and a high level of educational attainment achieve almost no welfare gain when pension premiums are set according to their income profile and according to the specific developments in household composition.

Table 5: Welfare gain from differentiating according to the level of educational attainment

\begin{tabular}{|l|l|}
\hline Education level & Consumption equivalent \\
\hline Low educational attainment & $0.9 \%$ \\
Medium educational attainment & $0.3 \%$ \\
High educational attainment & $0.1 \%$ \\
\hline
\end{tabular}

\section{$5 \quad$ Imposing borrowing constraints}

The results of our baseline model (Figure 4) indicate that people find it optimal to borrow from the pension fund in the first part of their career. In this section we recognize that borrowing from the pension fund can be unfeasible in practice. Hence, it is more realistic to take into account in our optimization that households cannot borrow from the pension fund. We solve the same optimal consumption and savings problem described by the models presented in Section 2, but now we implicitly impose the constraint that pension premiums cannot be negative. There exists no analytical solution to the model with borrowing constraints, thus we solve the model numerically.

Figure 11 presents the results obtained when we include a borrowing constraint. Households find it optimal to pay no pension contributions in the first part of the career and afterwards pay a pension contribution that increases with age. Optimal savings ratios are zero until the age of 32 years in the earner model and of 40 years in the family model (Figure 11c). Until these ages the borrowing constraint is binding and consumption is equal to net income. Later on, savings rates increase substantially and reach a level of 30 percent in the earner model and 37 percent in the family model. These levels are lower than if borrowing constraints do not exist (see Figure 4c) because it is no longer necessary to repay the amounts borrowed in the early stages of the life cycle.

Table 6: Optimal pension system versus current system - equivalent consumption

\begin{tabular}{|l|ll|}
\hline & $\begin{array}{l}\text { No borrowing } \\
\text { constraints }\end{array}$ & $\begin{array}{l}\text { With borrowing } \\
\text { constraints }\end{array}$ \\
\hline Family model & $3.4 \%$ & $2.8 \%$ \\
Earner model & $2.4 \%$ & $1.9 \%$ \\
\hline
\end{tabular}


(a) Optimal wealth

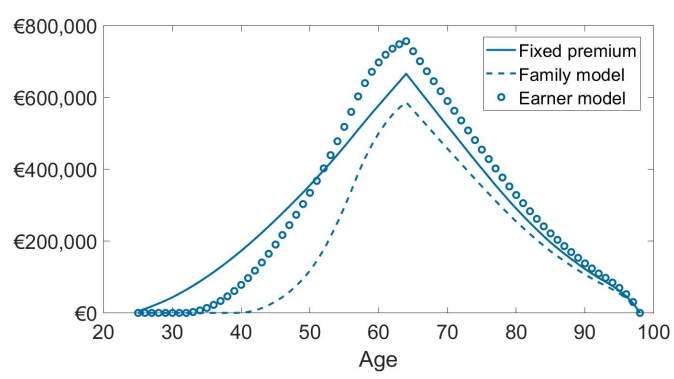

(c) Optimal savings ratio

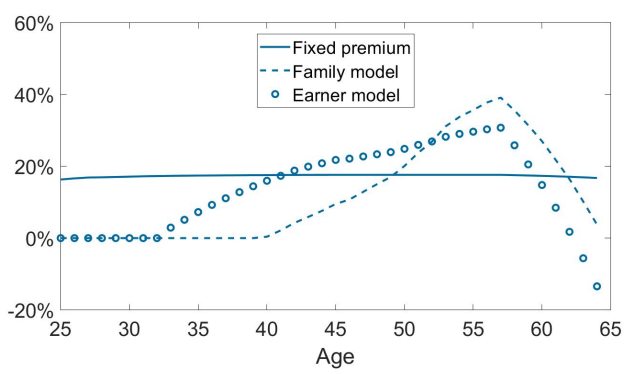

(b) Optimal consumption

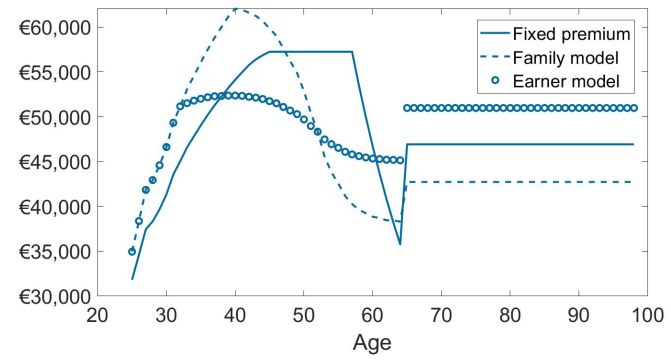

(d) Optimal pension benefits including AOW

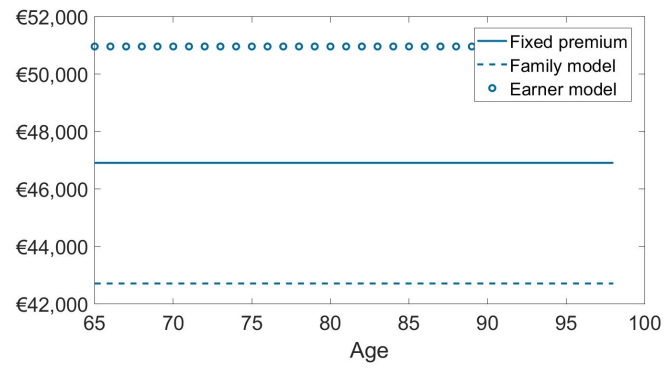

Figure 11: The model with the current pension system (solid line), family model with borrowing constraints (dashed line) and earner model with borrowing constraints (circles): optimal wealth, consumption, savings ratio and pension benefits.

Overall, we obtain more wealth accumulation when borrowing constraints exist: wealth peaks at almost 800 thousand euros in the case of the earner model and almost 600 thousand euros in the case of the family model, in both cases around 30 thousand euros higher than without the constraints. This results in pension benefits that are one to two thousand euros higher. The higher consumption at the older ages results from the imposed higher, that is non-negative, wealth formation at the younger ages. Optimal consumption at younger ages remains substantially higher than under the current fixed premium system even with borrowing constraints (see Figure 11b).

Table 6 shows that, as expected, the existence of borrowing constraints reduces the welfare gains that can be achieved with the optimization of pension premiums and pension ambition. However, a large part of the welfare gain still remains. Equivalent consumption equals 2.8 percent of annual consumption in the family model and 1.9 percent in the earner model, compared to respectively 3.4 percent and 2.4 percent without the borrowing constraints.

\section{Conclusion}

We determine in this paper how the introduction of a number of factors influences the optimal path of pension premiums and benefits. We use a deterministic life-cycle model in which households maximize lifetime utility from consumption by simultaneously determining the optimal life cycle paths of pension premiums during the working ages and pension benefits during retirement, assuming that these can be chosen freely. The optimization takes account of the fact that incomes generally rise during the working ages and that children are generally present in young households. Both factors contribute to a delay of optimal pension premiums to the later working ages. The welfare gain from optimizing pension premiums and benefits are quantitatively important. Taking into account the level of educational attainment of the main earner of the household brings only small changes in the path of optimal pension premium rates. There are modest welfare gains from taking into account the level of educational attainment in the case 
of households with a low educational attainment. Family size (i.e. number of children) has a large impact on optimal pension premiums and optimal pension ambition.

The contribution of this paper is that it offers an analytical framework for the optimization of the path of pension premiums and benefits that combines three factors - the upward sloping income profile, the presence of children in the beginning of a household's career and the level of educational attainment - and calibrates it to Dutch data. It shows that the optimal pension scheme in the Netherlands differs substantially from the current pension scheme in which pension premium rates are flat. The optimal scheme features premium rates that increase during working life. The level of pension benefits is lower than under the current pension system. This is due to the fact that children leave the household before the retirement age of the household head. Hence, the household needs to consume substantially less during the retirement phase than in the early years of the working life. Our calculations indicate that the optimization would raise welfare levels by an amount that equals that of a 3.4 percent increase in lifetime consumption if no borrowing constraints are imposed and 2.8 percent if, more realistically, we do impose these constraints.

We do not take into account a number of factors that would quantitatively change our results: for example, stochastic returns on pension assets and bequests. These would probably change the size of the optimal pension premiums. This is left for future research. However, we expect our main result regarding the upward sloping path of optimal pension premium rates to hold even with these extensions. We also expect our results to be similar to the ones obtained from a model in which households receive idiosyncratic income shocks around the average income path. The presence of income risk entices people to hold more liquid savings but it makes little difference for optimal pension savings. However, if people are myopic and do not hold liquid savings to cushion income shocks, the optimal pension premiums set by a social planner (or a pension fund) can be quite different to the results we obtain with the deterministic model. This is an interesting topic for future research ${ }^{8}$. We also find it important to consider other reasons why people borrow and save: for example study loans and mortgages. We expect that the introduction of these features would strengthen our results: households would have more incentives to delay the payment of pension premiums to later stages of their career and pension levels would be lower. Finally, lower pension premiums at younger ages result in less pension wealth at a certain age and reduce the possibility to retire early, if desired. Any policy conclusion should also take this aspect into consideration.

\footnotetext{
${ }^{8}$ First results of such an analysis indicate that the presence of income shocks has indeed a small effect on the optimal path of pension premiums and benefits if households make rational choices over consumption, saving for retirement and precautionary savings. Welfare gains turn out to be lower than in this paper. If people are myopic (for example they consume all their disposable income), then the optimal pension premium schedule involves higher premiums at young ages. See de Kok (2021), available on request.
} 


\section{References}

Alan, S. and Browning, M. (2010). Estimating intertemporal allocation parameters using synthetic residual estimation. The Review of Economic Studies, 77(4):1231-1261.

Attanasio, O. P. and Weber, G. (2010). Consumption and saving: models of intertemporal allocation and their implications for public policy. Journal of Economic literature, 48(3):693-751.

Bick, A. and Choi, S. (2013). Revisiting the effect of household size on consumption over the life-cycle. Journal of Economic Dynamics and Control, 37(12):2998-3011.

Cui, J. (2008). Dc pension plan defaults and individual welfare. Netspar Discussion Paper09/2008-034.

de Kok, C. (2021). Finding an optimal age-dependent pension premium path for Dutch households. Erasmus University of Rotterdam.

Domeij, D. and Klein, P. (2013). Should day care be subsidized? Review of Economic Studies, 80(2):568595.

Elmendorf, D. W. (1996). The effect of interest-rate changes on household saving and consumption: a survey. Finance and Economics Discussion Series 96-27, Board of Governors of the Federal Reserve System (U.S.).

French, E. (2005). The Effects of Health, Wealth, and Wages on Labour Supply and Retirement Behaviour. Review of Economic Studies, 72(2):395-427.

Fuchs-Schundeln, N. (2008). The response of household saving to the large shock of german reunification. American Economic Review, 98(5):1798-1828.

Gourinchas, P.-O. and Parker, J. A. (2002). Consumption Over the Life Cycle. Econometrica, 70(1):47-89.

Guvenen, F. and Smith, A. A. (2014). Inferring Labor Income Risk and Partial Insurance From Economic Choices. Econometrica, 82:2085-2129.

Havranek, T., Horvath, R., Irsova, Z., and Rusnak, M. (2015). Cross-country heterogeneity in intertemporal substitution. Journal of International Economics, 96(1):100-118.

Laitner, J. and Silverman, D. (2012). Consumption, retirement and social security: Evaluating the efficiency of reform that encourages longer careers. Journal of public economics, 96(7-8):615-634.

Ministry of Social Affairs and Employment (2020). Hoofdlijnennotitie pensioenakkoord. Technical report, SZW.

Nishiyama, S. and Smetters, K. (2007). Does social security privatization produce efficiency gains? The Quarterly Journal of Economics, 122(4):1677-1719.

Scholz, J. K., Seshadri, A., and Khitatrakun, S. (2006). Are Americans saving "optimally" for retirement? Journal of Political Economy, 114(4):607-643.

Scott, J., Shoven, J. B., Slavov, S., and Watson, J. G. (2021). Is automatic enrollment consistent with a life cycle model? Working Paper 28396, National Bureau of Economic Research.

SER (2019). Naar een nieuw pensioenstelsel. Ser-advies, Sociaal-Economische Raad.

Summers, L. H. (1984). The after tax rate of return affects private savings. American Economic Review, $74(2): 249-253$. 
Van Tilburg, I., Kuijpers, S., Nibbelink, A., and Zwaneveld, P. (2019). Gamma: Een Langetermijnmodel voor de Houdbaarheid van de Overheidsfinanciën, CPB Achtergronddocument. 


\section{Appendix}

\section{Derivation of the optimization problem}

This Appendix contains a step by step derivation of the equations presented in the paper. We start directly with the family model and mention what changes are must be implemented in the derivations in order to obtain the earner model.

The household maximizes her utility from consumption $u\left(c_{t}\right)$ by optimally choosing consumption $c_{t}$ and assets $a_{t}$ each period $t$ :

$$
\begin{gathered}
\max _{\left\{c_{t} a_{t}\right\}} \sum_{t=1}^{t=T} \beta^{t-1} \psi_{t} u\left(c_{t}\right) \\
u\left(c_{t}\right)=n_{t} \frac{\left(\frac{c_{t}}{e q_{t}}\right)^{1-\sigma}}{1-\sigma}
\end{gathered}
$$

where $\beta$ is the time preference parameter, $\psi_{t}$ is the probability to survive until time $t, n_{t}$ is the number of members in a household, $\sigma$ is the inverse of the elasticity of intertemporal subsitution and $e q_{t}$ equals the equivalence factor at time $t$. The equivalence factor reflects the fact that there are economies of scale from forming a family in terms of sharing some of the fixed costs (rent, car etc.). It reflects the number of adults and children in the household but not one to one (for example the first adult has a factor of 1 while the second adult has a factor of only 0.37 ). In the earner model, the number of household members $\left(n_{t}\right)$ is equal to 2 at every age because the consumption of children is not valued in the utility function. Consequently, this variable drops from the subsequent equations.

The per capita period by period individual budget constraint is given by:

$$
\begin{gathered}
y_{t}+R a_{t-1}+t r_{t}=c_{t}+\operatorname{tax}_{t}+a_{t}, \quad t<r a \\
\text { aow }_{t}+R a_{t-1}+t r_{t}=c_{t}+\operatorname{tax}_{t}+a_{t}, \quad t \geq r a
\end{gathered}
$$

where $y_{t}$ is the gross income including pension premiums, aow $w_{t}$ is the gross pension income from the first pillar of the Dutch pension system (AOW - Algemene Ouderdomswet), $R$ is the rate of return, $a_{t}$ is the wealth, the per capital transfers $t r_{t}$ come from the fact that a fraction of the population alive at time $t-1$ dies and the bequests are divided between the members still alive at time $t$. The size of the bequests left by the people who die is given by:

$$
B_{t}=R a_{t-1} l_{t-1}\left(1-\frac{\psi_{t}}{\psi_{t-1}}\right)
$$

where $R a_{t-1}$ is the per capita wealth accumulated by people alive at time $t-1, l_{t-1}$ is the number of people alive at time $t-1, \frac{\psi_{t}}{\psi_{t-1}}$ is the probability to survive between period $t-1$ and $t$ and $\left(1-\frac{\psi_{t}}{\psi_{t-1}}\right)$ is the probability to die between period $t-1$ and $t$. We divide total bequests among the people that are still alive at time $t$ :

$$
\frac{B_{t}}{l_{t}}=R a_{t-1} \frac{l_{t-1}}{l_{t}}\left(1-\frac{\psi_{t}}{\psi_{t-1}}\right)
$$

Next we take into account that the ratio of people alive at time $t$ and people alive at time $t-1$ is equal to the probability to survive between periods $t-1$ and $t$ :

$$
\frac{l_{t}}{l_{t-1}}=\frac{\psi_{t}}{\psi_{t-1}}
$$

We substitute relation 27 into 26 and obtain the per capita transfer coming from bequests:

$$
\begin{aligned}
& \frac{B_{t}}{l_{t}}=R a_{t-1} \frac{\psi_{t-1}}{\psi_{t}}\left(1-\frac{\psi_{t}}{\psi_{t-1}}\right) \\
& t r_{t}=\frac{B_{t}}{l_{t}}=R a_{t-1}\left(\frac{\psi_{t-1}}{\psi_{t}}-1\right)
\end{aligned}
$$


Finally, we substitute 29 in the period by period per capita budget constraint from relation 23 and obtain:

$$
\begin{gathered}
y_{t}+R a_{t-1}+R a_{t-1}\left(\frac{\psi_{t-1}}{\psi_{t}}-1\right)=c_{t}+\operatorname{tax} x_{t}+a_{t} \\
y_{t}+R a_{t-1}-R a_{t-1}+R a_{t-1} \frac{\psi_{t-1}}{\psi_{t}}=c_{t}+\operatorname{tax} x_{t}+a_{t} \\
y_{t}+R a_{t-1} \frac{\psi_{t-1}}{\psi_{t}}=c_{t}+\operatorname{tax}_{t}+a_{t} \\
y_{t} \psi_{t}+R a_{t-1} \psi_{t-1}=c_{t} \psi_{t}+\operatorname{tax} \psi_{t}+a_{t} \psi_{t}
\end{gathered}
$$

In a similar way, the individual constraint after the retirement age (equation 24) becomes:

$$
a o w_{t} \psi_{t}+R a_{t-1} \psi_{t-1}=c_{t} \psi_{t}+\operatorname{tax}_{t} \psi_{t}+a_{t} \psi_{t}
$$

We use the individual constraints 30 and 31 to obtain the lifetime budget constraint:

$$
\begin{array}{r}
\psi_{1} c_{1}+\frac{\psi_{2} c_{2}}{R}+\ldots+\frac{\psi_{T} c_{T}}{R^{T-1}}+\psi_{1} \operatorname{tax}_{1}+\frac{\psi_{2} \operatorname{tax}_{2}}{R}+\ldots+\frac{\psi_{T} \operatorname{tax}_{T}}{R^{T-1}}=\ldots \\
\psi_{1} y_{1}+\frac{\psi_{2} y_{2}}{R}+\ldots+\frac{\psi_{r a-1} y_{r a-1}}{R^{r a-2}}+\frac{\psi_{r a} a o w_{r a}}{R^{r a-1}}+\ldots+\frac{\psi_{T} a o w_{T}}{R^{T-1}}
\end{array}
$$

The consumption can be described by:

$$
\begin{gathered}
c_{t}=\left(y_{t}-p_{t}\right)\left(1-\omega_{t}\right), \quad t<r a \\
c_{t}=\left(a o w_{t}-p_{t}\right)\left(1-\omega_{t}\right), \quad t \geq r a
\end{gathered}
$$

where $p_{t}$ equals the amount of pension money (either being saved or dis-saved) and $\omega_{t}$ equals the percentage of tax on income net of pension premiums paid at age $t: 38 \%$ during the working life and $20 \%$ during retirement. For simplicity, average and marginal tax rates in both phases are set equal. ${ }^{9}$ The absolute values of tax are equal to $\operatorname{tax}_{t}=\left(y_{t}-p_{t}\right) \omega_{t}$, so expenditures (consumption and tax) can be rewritten as 10 :

$$
\begin{gathered}
c_{t}+\operatorname{tax}_{t}=\left(y_{t}-p_{t}\right)\left(1-\omega_{t}\right)+\left(y_{t}-p_{t}\right) \omega_{t}=\frac{c_{t}}{1-\omega_{t}}, \quad t<r a \\
c_{t}+\operatorname{tax}_{t}=\left(\text { aow }_{t}-p_{t}\right)\left(1-\omega_{t}\right)+\left(a o w_{t}-p_{t}\right) \omega_{t}=\frac{c_{t}}{1-\omega_{t}}, \quad t \geq r a
\end{gathered}
$$

Therefore, equation 32 can be rewritten as:

$\frac{\psi_{1} c_{1}}{1-\omega_{1}}+\frac{\psi_{2} c_{2}}{R\left(1-\omega_{2}\right)}+\ldots+\frac{\psi_{T} c_{T}}{R^{T-1}\left(1-\omega_{T}\right)}=\psi_{1} y_{1}+\psi_{2} y_{2} R+\ldots+\frac{\psi_{r a-1} y_{r a-1}}{R^{r a-2}}+\frac{\psi_{r a} a o w_{r a}}{R^{r a-1}}+\ldots+\frac{\psi_{T} a o w_{T}}{R^{T-1}}$

\footnotetext{
${ }^{9}$ In reality however average and marginal tax rates differ, both in size and in their impact. A high average tax rate reduces income and thus increases the marginal utility of consumption. As a result it increases the allocation of consumption to years in which the average tax rate is relatively high, reducing saving. A high marginal tax rate has the opposite effect. It reflects that a large part of pension savings goes untaxed and thus stimulates it in these years.

${ }^{10}$ In the Netherlands around 70 percent of pension premiums is paid by the employer, and 30 percent by the employee. Our modelling of the effects on net incomes and consumption nonetheless assumes that the full 100 percent is paid by the employee. This follows from the fact that we assume that, as a result of international competition, employers don't have the financial room to raise labour costs and that therefore these costs are fixed. This implies that the employers part of the pension premiums, and changes therein, are effectively borne by the employee. An increase of pension premiums therefore does not affect labour costs and is fully absorbed by the employee in the form of a pro tanto reduction of gross incomes (labour costs minus the employers payments). This means that the tax base is reduced as well and that the employers pension premium therefore has the same effect on taxes as the pension premiums paid by the employees. Both pro tanto reduce the tax base.
} 
In other words, the present value of total expenditures (consumption and tax for pension benefits) over the lifetime of a household (left side of the equation) must equal the present value of total incomes received. The problem that he household solves (21) becomes:

$$
\begin{array}{r}
\max _{\left\{c_{t}, a_{t}\right\}} \sum_{t=1}^{t=T} \beta^{t-1} \psi_{t} n_{t} \frac{\left(\frac{c_{t}}{e q_{t}}\right)^{1-\sigma}}{1-\sigma}+\lambda\left(\psi_{1} y_{1}+\frac{\psi_{2} y_{2}}{R}+\ldots+\frac{\psi_{r a-1} y_{r a-1}}{R^{r a-2}}+\frac{\psi_{r a} a o w_{r a}}{R^{r a-1}}+\ldots+\frac{\psi_{T} a o w_{T}}{R^{T-1}}\right. \\
\left.-\frac{\psi_{1} c_{1}}{1-\omega_{1}}-\frac{\psi_{2} c_{2}}{R\left(1-\omega_{2}\right)}-\ldots-\frac{\psi_{T} c_{T}}{R^{T-1}\left(1-\omega_{T}\right)}\right)
\end{array}
$$

The first order conditions of the above maximization problem are:

$$
\begin{aligned}
n_{1}\left(\frac{1}{e q_{1}}\right)^{1-\sigma} c_{1}^{-\sigma} & =\frac{\lambda}{\left(1-\omega_{1}\right)} \\
\beta^{t-1} n_{t}\left(\frac{1}{e q_{t}}\right)^{1-\sigma} c_{t}^{-\sigma} & =\frac{\lambda}{R^{t-1}\left(1-\omega_{t}\right)} \\
\psi_{1} y_{1}+\frac{\psi_{2} y_{2}}{R}+\ldots+\frac{\psi_{r a-1} y_{r a-1}}{R^{r a-2}}+\frac{\psi_{r a} a o w_{r a}}{R^{r a-1}}+\ldots+\frac{\psi_{T} a o w_{T}}{R^{T-1}} & =\frac{\psi_{1} c_{1}}{1-\omega_{1}}+\frac{\psi_{2} c_{2}}{R\left(1-\omega_{2}\right)}+\ldots+\frac{\psi_{T} c_{T}}{R^{T-1}\left(1-\omega_{T}\right)}
\end{aligned}
$$

Rewriting the above first order conditions for consumption gives:

$$
c_{1}^{-\sigma}=(\beta R)^{t-1}\left(\frac{n_{t}}{n_{1}}\right)\left(\frac{e q_{1}}{e q_{t}}\right)^{1-\sigma}\left(\frac{1-\omega_{t}}{1-\omega_{1}}\right) c_{t}^{-\sigma}, \forall t=2, . ., T
$$

It follows that the relationship between first period consumption $c_{1}$ and the consumption in period $t c_{t}$ is given by:

$$
c_{t}=c_{1}(\beta R)^{\frac{t-1}{\sigma}}\left(\frac{n_{t}}{n_{1}}\right)^{\frac{1}{\sigma}}\left(\frac{e q_{1}}{e q_{t}}\right)^{\frac{1-\sigma}{\sigma}}\left(\frac{1-\omega_{t}}{1-\omega_{1}}\right)^{\frac{1}{\sigma}}, \forall t=2, . ., T
$$

Next, we substitute equation (43) in the life-time budget constraint of the household from equation 37 :

$$
\begin{array}{r}
\frac{\psi_{1} c_{1}}{1-\omega_{1}}+\frac{\psi_{2} c_{1}(\beta R)^{\frac{1}{\sigma}}\left(\frac{n_{2}}{n_{1}}\right)^{\frac{1}{\sigma}}\left(\frac{e q_{1}}{e q_{2}}\right)^{\frac{1-\sigma}{\sigma}}\left(\frac{1-\omega_{2}}{1-\omega_{1}}\right)^{\frac{1}{\sigma}}}{R\left(1-\omega_{2}\right)}+\ldots+\frac{\psi_{T} c_{1}(\beta R)^{\frac{T-1}{\sigma}}\left(\frac{n_{T}}{n_{1}}\right)^{\frac{1}{\sigma}}\left(\frac{e q_{1}}{e q_{T}}\right)^{\frac{1-\sigma}{\sigma}}\left(\frac{1-\omega_{T}}{1-\omega_{1}}\right)^{\frac{1}{\sigma}}}{R^{T-1}\left(1-\omega_{T}\right)} \\
=\psi_{1} y_{1}+\frac{\psi_{2} y_{2}}{R}+\ldots+\frac{\psi_{r a-1} y_{r a-1}}{R^{r a-2}}+\frac{\psi_{r a} a o w_{r a}}{R^{r a-1}}+\ldots+\frac{\psi_{T} a o w_{T}}{R^{T-1}}
\end{array}
$$

Now we can derive a closed-form solution for the first period consumption of the household:

$$
c_{1}=\frac{\psi_{1} y_{1}+\frac{\psi_{2} y_{2}}{R}+\ldots+\frac{\psi_{r a-1} y_{r a-1}}{R^{r a-2}}+\frac{\psi_{r a} a o w_{r a}}{R^{r a-1}}+\ldots+\frac{\psi_{T} a o w_{T}}{R^{T-1}}}{\frac{\psi_{1}}{\left(1-\omega_{1}\right)}+\frac{\psi_{2}(\beta R)^{\frac{1}{\sigma}}\left(\frac{n_{2}}{n_{1}}\right)^{\frac{1}{\sigma}}\left(\frac{e q_{1}}{e q_{2}}\right)^{\frac{1-\sigma}{\sigma}}\left(\frac{1-\omega_{2}}{1-\omega_{1}}\right)^{\frac{1}{\sigma}}}{R\left(1-\omega_{2}\right)}+\ldots+\frac{\psi_{T}(\beta R)^{\frac{T-1}{\sigma}}\left(\frac{n_{T}}{n_{1}}\right)^{\frac{1}{\sigma}}\left(\frac{e q_{1}}{e q_{T}}\right)^{\frac{1-\sigma}{\sigma}}\left(\frac{1-\omega_{T}}{1-\omega_{1}}\right)^{\frac{1}{\sigma}}}{R^{T-1}\left(1-\omega_{T}\right)}}
$$

Now we derived a formula for consumption in the first period, we see that $c_{1}$ depends solely on (fixed) input variables and has therefore only one solution. Combining this observation with equation 39, we note that there is only a single solution for $\lambda$, since $n_{1}, e q_{1}, \omega_{1}$ and $\sigma$ are input variables and $c_{1}$ has a single solution. Therefore, there is only one solution for consumption at time $t$ for all values of $t$ (see equation 43). Thus our solution is the global optimum, as there are no other local optimums. 